\title{
Antimicrobial resistant and virulence genes profiles of some Gram-negative bacteria from clinical isolates at Usmanu Danfodiyo University Teaching Hospital, Sokoto, Nigeria
}

\author{
Tanko Nuhu, ${ }^{1, A-D, F}$, Eugene Ong Boon Beng ${ }^{2, B-F} \oplus$, Rebecca Olajumoke Bolaji ${ }^{3, A, C-F} \oplus$, \\ Tolulope Adebola Olayinka ${ }^{4, A, C-F \oplus}$, Busayo Olalekan Olayinka ${ }^{3, A, C-F} \oplus$, Mohammed Yahaya ${ }^{5, B-F}$ \\ ${ }^{1}$ Usmanu Danfodiyo University, Sokoto, Nigeria \\ 2 Universiti Sains Malaysia, Malaysia \\ ${ }^{3}$ Ahmadu Bello University, Zaria, Nigeria \\ ${ }^{4}$ Ahmadu Bello University Teaching Hospital, Shika, Nigeria \\ ${ }^{5}$ Usmanu Danfodiyo University Teaching Hospital, Sokoto, Nigeria \\ A - Research concept and design, B - Collection and/or assembly of data, C - Data analysis and interpretation, \\ $D$ - Writing the article, $E$ - Critical revision of the article, $F$ - Final approval of article
}

\begin{abstract}
Tanko Nuhu, Eugene Ong Boon Beng, Rebecca Olajumoke Bolaji, Tolulope Adebola Olayinka, Busayo Olalekan Olayinka, Mohammed Yahaya. Antimicrobial resistant and virulence genes profiles of some Gram-negative bacteria from clinical isolates at Usmanu Danfodiyo University Teaching Hospital, Sokoto, Nigeria. J Pre-Clin Clin Res. 2020; 14(2): 52-57. doi: 10.26444/jpccr/123793
\end{abstract}

\section{Abstract}

Introduction and objective. Infections due to multidrug-resistant (MDR) Enterobacteriaceae are an ongoing global threat in their management. The aim of the study was to investigate the antiimicrobial resistance (AMR) and virulence gene profiles of MDR Gram-negative isolates in Sokoto, north-west Nigeria.

Materials and method. A total of 578 clinical samples were collected from patients. Suspected Gram-negative bacteria were isolated from these clinical samples: vaginal swab, pus, stool, blood, wound swab and urine, using Gram-staining and conventional biochemical reactions. These isolates were further identified with an identification kit (Microgen-GN-A), and tested against a panel of 11 antibiotics. A single polymerase chain reaction (PCR) assay targeting 13 virulence gene related to adhesion (fimH, papC, and sfaS), iron chelation (iutA, and fyuA), toxins (astA, stx1, stx2, and eaeA), biofilm (bssS), and serum resistance (traT, iss, and kapsMTII) encoding genes were evaluated.

Results. A total of $276 \mathrm{Gram}$-negative isolates were identified using the Gram stain and biochemical reactions. These organisms were further confirmed with identification kit. Of the 276 isolates, 36 organisms of interest (23 Escherichia coli, 4 Klebsiella pneumoniae and 9 Proteus mirabilis) were identified. Other Gram-negative isolates accounted for the remaining $86.9 \%$. The majority of the isolates were resistant to cefixime (100\%) and partially resistant to amikacin (19.4\%).The virulence genes bssS (58.3\%), fimH (44.4\%), and iutA (44.4\%) were the most prevalent, whereas kapsMTII (5.6\%) and stx2 (2.8\%) were least detected, while astA was not detected in any of the isolates.

Conclusion. The study elucidated the prevalence of antibiotic resistance and virulence genes in Gram-negative bacteria from clinical isolates in Sokoto, north-western Nigeria. The majority of the isolates were MDR, thereby posing a public health risk.

\section{Key words}

virulence factors, Enterobacteriaceae, anti-microbial resistance, north-west Nigeria

\section{INTRODUCTION}

The rapid and accurate identification of pathogens involved in infection is the first step in the curtailment of infectious disease [1,2]. It is crucial to know the pathogens' antimicrobial resistance profiles so that the patients receive the correct antibiotics for effective treatment. Antimicrobial resistance (AMR) occurs when microorganisms are able to overcome drugs that target them, resulting to ineffective treatment [3]. The growing problem due to infections caused by multi-drug resistant (MDR) Gram-negative bacteria have been reported worldwide, and the problem is compounded by limited new antibiotic production in the pipeline [4]. MDR occurs when a bacterium is resistant to more than one antibiotic [5], which

Address for correspondence: Tanko Nuhu, Usmanu Danfodiyo University Sokoto, Nigeria

E-mail:nuhu.tanko@yahoo.com

Received: 19.04. 2020; accepted: 09.06.2020; first published: 22.06.2020 is common in Gram-negative bacteria such as Escherichia coli (E. coli) and Klebsiella pneumoniae (K. pneumoniae), making them a global threat [6]. Infections caused by these MDR Gram-negative bacteria can lead to prolonged hospital stays and higher mortality rates [7]. A report by Jasovsky et al. estimated that deaths from drug-resistant infections are projected to increase from the current 700 thousand to 10 million annually, and cost estimates will be as high as US $\$ 100$ trillion worldwide by 2050 [8].

Variation in AMR patterns in individual countries is linked to the standard use of antimicrobial drugs in the respective countries [9]. Between 2000-2010, the global consumption of antibiotics in human medicine rose by $40 \%$; however, this figure masks patterns of declining usage in some countries and rapid growth in others [9]. Numerous relationships exist between AMR and bacterial virulence, and the spread of clones combining many antibiotic resistances and a high virulence level is an increasing threat [10]. Virulence factors 
comprise of mechanisms that allow pathogenic bacteria to cause infections [11]. These bacterial virulence factors are mostly encoded by or are associated with mobile genetic elements, such as plasmids, phages, transposons and insertion elements, where a very large number of these determinants are located within pathogenicity islands (PAIs) [11]. PAI carries an array of virulence genes whose product contributes to the pathogenicity of the bacterium. Chapman et al., stated that the acquisition of virulence genes confers an evolutionary pathway to the pathogenicity to microorganisms [12], and understanding the virulence factors carried by a strain enables determination of the pathogenic potential of the strain.

Studies on the prevalence of AMR and virulence genes in Gram-negative bacteria has been reported in various parts of Nigeria. In Sokoto, north-western Nigeria, however, there is dearth of information and studies regarding AMR and virulence genes. Therefore, this study focuses on AMR patterns and the virulence genes in E. coli, K. pneumoniae and P. mirabilis isolated from clinical samples at UDUTH Sokoto.

\section{OBJECTIVE}

The aim of this study was to examine the AMR pattern and virulence genes profiles of selected Gram-negative bacteria, specifically E. coli, K. pneumoniae, and Proteus mirabilis (P. mirabilis), due to their emerging threat in Sokoto, northwest Nigeria.

\section{MATERIALS AND METHOD}

Sample collection, bacterial isolation and identification. The ethical committee of UDUTH Sokoto approved the protocol for this study with reference number: UDUTH/ HREC/2019/ No.611.

A total of 578 clinical samples were collected from patients between January - June 2019. Suspected Gram-negative bacteria were isolated from the clinical samples: vaginal swab, pus, stool, blood, wound swab and urine, in Department of Microbiology at Usmanu Danfodiyo University Teaching Hospital. The exclusion criteria ensured that only one isolate is recovered from the same patient. Only samples from patients over 18 years of age were used in the study. An informed consent form was signed or thumb printed by all participants before sample collection. Information was coded to ensure the anonymity of the patients.

The isolates were cultured on Mueller Hinton Agar (MHA) plates, screened by Gram staining and identified by biochemical methods. The identities were further confirmed using a microbial identification kit (Microgen GN-A ID Kit) according to the manufacturer's instructions. The isolates were stored at $-20^{\circ} \mathrm{C}$ in Mueller Hinton Broth (MHB) until needed for further analysis. All molecular analysis was carried out at the Institute for Research in Molecular Medicine (INFORMM) at the Universiti Sains Malaysia (USM), Malaysia.

Antibiotic susceptibility determination. The agar disc diffusion method was used to determine the susceptibility of the organisms against 11 antibiotics used in the management of most Gram-negative bacteria. Results were interpreted according to the Clinical and Laboratory Standard Institute
(CLSI, 2016). The antibiotics tested were sourced from Oxoid, $\mathrm{UK}$, and included; ampicillin/sulbactam (SAM, 10/10 $\mu \mathrm{g}$ ), gentamicin $(\mathrm{CN}, 10 \mu \mathrm{g})$, ciprofloxacin $(\mathrm{CIP}, 5 \mu \mathrm{g})$, meropenem (MEM, $10 \mu \mathrm{g})$, imipenem (IPM, $10 \mu \mathrm{g}$ ), amikacin (AK, $10 \mu \mathrm{g}$ ), cefixime (CFM, $5 \mu \mathrm{g})$, chloramphenicol (C, $30 \mu \mathrm{g})$, nitrofurantoin (F, $300 \mu \mathrm{g})$, cefotaxime (CTX, $30 \mu \mathrm{g})$, and ceftazidime (CAZ, $30 \mu \mathrm{g})$. Standard strains E. coli ATCC 25922 and K. pneumoiniae ATCC 700603 were used as positive and negative control, respectively.

Extraction of bacterial genomic DNA. All isolates were prepared by inoculating 1-2 colonies into $5 \mathrm{ml}$ freshly prepared Luria Bertani (LB) Broth, and incubated at $37^{\circ} \mathrm{C}$ in a shaker (200 rpm) for 24 hours. DNA was extracted using the boiling method [13].

All DNA samples were subjected to agarose gel electrophoresis to ascertain the presence of DNA. A $0.8 \%$ agarose gel was prepared in 0.5 Tris-borate-EDTA (TBE) buffer. All DNA samples were gel electrophoresed at 100 $\mathrm{V}, 400 \mathrm{~mA}$ for 25 minutes. The gels were then immersed in ethidium bromide solution $(0.5 \mu \mathrm{g} / \mathrm{ml})$ for 20 minutes and de-stained in distilled water for 10 minutes. The sizes of the amplicons were determined by comparison with a 100bp- was captured (GeneFlash, Syngene).

Detection of virulence genes by PCR. A single PCR assay targeting 13 virulent genes related to adhesion $(f i m \mathrm{H}, p a p \mathrm{C}$, and $s f a S$ ), iron chelation (iutA, and $f y u \mathrm{~A}$ ), toxins (ast A, stx1, stx2, and eaeA), biofilm (bssS), and serum resistance (traT, iss, and kapsMTII) encoding genes that are associated with Enterobacteriaceae, were evaluated in the study. The oligonucleotide sequences are listed in Table 1.

Table 1. Oligonucleotide sequences for virulence genes

\begin{tabular}{|c|c|c|c|}
\hline S/No & Genes & Nucleotide sequence $5^{\prime}-3^{\prime}$ & Size (bp) \\
\hline \multirow[t]{2}{*}{1} & $f i m \mathrm{H}$ & TACTGCTGATGGGCTGGT & 632 \\
\hline & & GCCGGAGAGGTAATACCC & \\
\hline \multirow[t]{2}{*}{2} & papC & TGGATTGTCAGCCTCAAG & 320 \\
\hline & & CACTGACGCCGAAAGACG & \\
\hline \multirow[t]{2}{*}{3} & sfas & GTGGATACGACGATTACT & 242 \\
\hline & & CCGCCAGCATTCCCTGTA & \\
\hline \multirow[t]{2}{*}{4} & iutA & ATCAGAGGGACCAGCACG & 254 \\
\hline & & TTCAGAGTCAGTTTCATG & \\
\hline \multirow[t]{2}{*}{5} & fyuA & ATACCACCGCTGAAACGC & 278 \\
\hline & & CGCAGTAGGCACGATGTT & \\
\hline \multirow[t]{2}{*}{6} & stx 1 & ATAAATCGCCATTCGTTG & 180 \\
\hline & & AGAACGCCCACTGAGATC & \\
\hline \multirow[t]{2}{*}{7} & stx 2 & GGCACTGTCTGAAACTGC & 255 \\
\hline & & TCGCCAGTTATCTGACAT & \\
\hline \multirow[t]{2}{*}{8} & eaeA & GACCCGGCACAAGCATAA & 384 \\
\hline & & CCACCTGCAGCAACAAGA & \\
\hline \multirow[t]{2}{*}{9} & $\operatorname{traT}$ & GGTGTGGTGCGATGAGCA & 288 \\
\hline & & CACGGTTCAGCCATCCCT & \\
\hline \multirow[t]{2}{*}{10} & Iss & GCAATGCTTATTACAGGA & 256 \\
\hline & & AGCAATATACCCGGGCTT & \\
\hline \multirow[t]{2}{*}{11} & kapsMTII & GCGCATTTGCTGATACTG & 270 \\
\hline & & CATCCAGACGATAAGCAT & \\
\hline \multirow[t]{2}{*}{12} & astA & GCCATCAACACAGTAT & 106 \\
\hline & & ATGAGTGACGGCTTTGTAGT & \\
\hline \multirow[t]{2}{*}{13} & bssS & GATTCAATTITGGCGATT & 256 \\
\hline & & TAATGAAGTCATTCAGAC & \\
\hline
\end{tabular}

All references e adapted from El-Shaer et al. [14]. 
Statistical analysis. All data were manually entered and analyzed in MS Excel 2010.

\section{RESULTS}

Bacterial isolation and identification. A total of 276 Gramnegative bacteria were isolated from the 578 clinical samples. Of these, 36 comprised of E. coli (23), K. pneumoniae (4), and P. mirabilis (9), were identified using biochemical tests and an identification kit. 240 isolates were identified as other Gramnegative Enterobacteriaceae and were excluded from the study. Table 2 shows the distribution of the Gram-negative bacteria.

Table 2. Distribution of Gram-negative isolates from clinical samples

\begin{tabular}{|c|c|c|c|c|c|c|c|}
\hline Organism & V/swab & Pus & Stool & Blood & W/swab & Urine & Total \\
\hline E. coli & 5 & 1 & 5 & 0 & 2 & 10 & 23 \\
\hline P. mirabilis & 2 & 1 & 1 & 0 & 2 & 3 & 9 \\
\hline K. pneumoniae & 0 & 0 & 0 & 0 & 1 & 3 & 4 \\
\hline K. oxytoca & 4 & 2 & 2 & 2 & 7 & 19 & 36 \\
\hline E. gergoviae & 2 & 2 & 2 & 2 & 2 & 27 & 37 \\
\hline E.aerogenes & 3 & 2 & 5 & 0 & 3 & 15 & 28 \\
\hline S. arizonae & 2 & 1 & 4 & 1 & 0 & 29 & 37 \\
\hline C. freundii & 3 & 3 & 3 & 1 & 5 & 9 & 24 \\
\hline C. diversus & 1 & 0 & 2 & 0 & 1 & 3 & 7 \\
\hline H. alvei & 2 & 1 & 1 & 0 & 1 & 2 & 7 \\
\hline C. sakazakii & 0 & 2 & 5 & 0 & 3 & 6 & 16 \\
\hline A. Iwoffii & 3 & 2 & 1 & 0 & 1 & 9 & 16 \\
\hline S. marcescens & 1 & 1 & 2 & 1 & 1 & 4 & 10 \\
\hline S. liquefaciens & 0 & 0 & 1 & 1 & 1 & 5 & 8 \\
\hline P. vulgaris & 2 & 0 & 3 & 0 & 2 & 7 & 14 \\
\hline TOTAL & 30 & 18 & 37 & 8 & 32 & 151 & 276 \\
\hline
\end{tabular}

K. oxytoca - Klebsiella oxytoca; E. gergoviae - Enterobacter gergoviae; E. aerogenes Enterobacter aerogenes; S. arizonae - Salmonella arizonae; $C$. freundii - Citrobacter freundii; C. diversus - Citrobacter diversus; H. alvei - Hafnia alvei; C. sakazakii - Cronobacter sakazakii; A. Iwoffii - Acinetobacter Iwoffii; S. marcescens - Serratia marcescens; S. liquefaciens - Serratia liquefaciens; P. vulgaris - Proteus vulgaris V/swab - Vaginal swab; W/swab - Wound swab.

Antibiotic susceptibility determination. Antibiotic resistance profile of the 36 Gram-negative isolates is shown in Figure 1. Low resistance was recorded to amikacin (19.4\%) whereas gentamicin has a resistance rate of $77.0 \%$. Resistance to the carbapenems was less than $50 \%$ (44.4\% to meropenem and $47.2 \%$ to imipenem). For the beta-lactam/beta-lactam inhibitor (ampicillin/sulbactam), resistant was as high as $83.3 \%$. The cephalosporins depicted a resistant rate greater than $75.0 \%$ (77.8\% in ceftazidime, $97.2 \%$ in cefotaxime to $100.0 \%$ in cefixime).

Detection of virulence genes by PCR. The AMR and virulence gene profiles for E. coli, P. mirabilis and K. pneumoniae are summarized in Tables 3, 4 and 5, respectively. Firstly, ast A, for which codes for EAST1 toxin was not detected in any of the isolates; however, kapsMTII and stx2 had the lowest presence among the isolates with an incidence of 2 and 1 , respectively. The most prevalent detected virulence gene was bss $\mathrm{S}$, which is found in E. coli, K. pneumoniae, and P. mirabilis. This is followed by fim $\mathrm{H}$ and iutA, observed mostly in E. coli and $P$. mirabilis. Four isolates were found to be avirulent, while in 7 isolates, only a single virulence genes was detected.

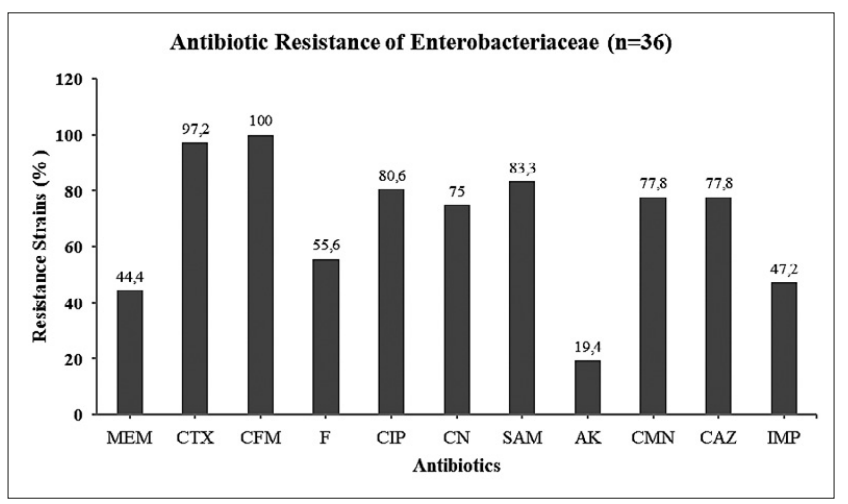

Figure 1. Antibiotic resistance profile of $36 \mathrm{Gram}$-negative isolates from clinical samples.

MEM - Meropenem; CTX - Cefotaxime; CFM - Cefixime; F - Nitrofurantoin; CIP - Ciprofloxacin; CN - Gentamicin; SAM - Sulbactam/Ampicillin; AK - Amikacin; CMN - Chloramphenicol; CAZ - Ceftazidime; IMP - Imipenem.

Table 3. Virulence genes detected with corresponding resistance pattern and their clinical source for E. coli

\begin{tabular}{|c|c|c|c|}
\hline Isolates & Source & Virulence factors (genes) & Antibiotics resisted \\
\hline coli 1 & Stool & fim $\mathrm{H}$, eaeA, iut $\mathrm{A}$, bss $\mathrm{S}$ & $\begin{array}{l}\text { MEM, CTX, CFM, CIP, SAM, AK, } \\
\text { C, CAZ }\end{array}$ \\
\hline coli 2 & Urine & $\begin{array}{l}\text { fim } \mathrm{H}, \text { papC, eaeA, iutA, } \\
\text { fyuA, traT, bssS }\end{array}$ & CTX, CFM, F, CIP, CN, SAM, CAZ \\
\hline E. coli 3 & Urine & papC, iutA, kapsMTII, bssS & $\begin{array}{l}\text { MEM, CTX, CFM, F, CIP, CN, SAM, } \\
\text { AK, C, CAZ, IPM }\end{array}$ \\
\hline E. coli 4 & Urine & $f i m \mathrm{H}, s f a \mathrm{~S}$, bssS & $\begin{array}{l}\text { CTX, CFM, F, CIP, CN, SAM, C, } \\
\text { CAZ, IPM }\end{array}$ \\
\hline E. coli 5 & Stool & bssS & CTX, CFM, F, CN, SAM, C, CAZ \\
\hline E. coli 6 & Urine & $f i m \mathrm{H}$, stx 1, eaeA, iss, bss $\mathrm{S}$ & $\begin{array}{l}\text { MEM, CTX, CFM, CIP, CN, SAM, C, } \\
\text { CAZ, IPM }\end{array}$ \\
\hline E. coli 7 & Stool & stx1, sfaS, traT, iss, bssS & CFM, F, CN, SAM, C, CAZ \\
\hline E. coli 8 & Urine & $f i m \mathrm{H}$, bss S & $\begin{array}{l}\text { CTX, CFM, F, CIP, CN, SAM, C, } \\
\text { CAZ, IPM }\end{array}$ \\
\hline E. coli 9 & Urine & $f i m \mathrm{H}$ & $\begin{array}{l}\text { MEM, CTX, CFM, CIP, SAM, AK, } \\
\text { C, IPM }\end{array}$ \\
\hline E. coli 10 & Stool & $\begin{array}{l}\text { fimH, stx1, sfaS, fyuA, traT, } \\
\text { bssS }\end{array}$ & MEM, CTX, CFM, F, CIP, SAM, C \\
\hline E. coli 11 & Urine & $f i m \mathrm{H}, e a e \mathrm{~A}$ & CTX, CFM, CIP, SAM, CAZ, IPM \\
\hline E. coli 12 & Urine & eaeA, iutA, fyuA, bssS & MEM, CTX, CFM, CIP, CN, C, CAZ \\
\hline E. coli 13 & Stool & fim $\mathrm{H}$, iutA & $\begin{array}{l}\text { CTX, CFM, F, CIP, CN, SAM, C, } \\
\text { CAZ, IPM }\end{array}$ \\
\hline E. coli 14 & Urine & fimH, papC & CTX, CFM, F, CIP, CN, CAZ \\
\hline E. coli 15 & Urine & papC & $\begin{array}{l}\text { MEM, CTX, CFM, F, CIP, CN, C, } \\
\text { CAZ, IPM }\end{array}$ \\
\hline E. coli 16 & Urine & fimH, sfaS, iutA, fyuA, bssS & CTX, CFM, CN, SAM, C, CAZ, IPM \\
\hline E. coli 17 & Stool & $\begin{array}{l}\text { fimH, papC, eaeA, iutA, fyuA, } \\
\text { traT, bssS }\end{array}$ & $\begin{array}{l}\text { CTX, CFM, CIP, CN, SAM, CAZ, } \\
\text { IPM }\end{array}$ \\
\hline E. coli 18 & Urine & $f i m H$, iss, bss $S$ & CTX, CFM, CIP, SAM, C, CAZ \\
\hline E. coli 19 & HVS & $\begin{array}{l}\text { papC, stx 1, sfas, eaeA, iutA, } \\
\text { iss, bssS }\end{array}$ & MEM, CTX, CFM, F, CIP, CN, SAM \\
\hline E. coli 20 & Urine & Nil & CTX, CFM, F, C \\
\hline E. coli 21 & Stool & $\begin{array}{l}\text { stx2, papC, stx1, sfaS, eaeA, } \\
\text { iutA, traT, kapsMTII, bssS }\end{array}$ & CTX, CFM, F, CIP, CN, SAM, C, CAZ \\
\hline E. coli 22 & Stool & papC, sfaS, iutA, bssS & $\begin{array}{l}\text { MEM, CTX, CFM, CIP, SAM, AK, } \\
\text { C, IPM }\end{array}$ \\
\hline E. coli 23 & Urine & $\begin{array}{l}\text { fimH, papC, eaeA, traT, } \\
\text { iss, bssS }\end{array}$ & $\begin{array}{l}\text { MEM, CTX, CFM, CIP, SAM, C, } \\
\text { CAZ, CN }\end{array}$ \\
\hline
\end{tabular}


Table 4. Virulence genes detected with corresponding resistance pattern and their clinical source for P. mirabilis

\begin{tabular}{|c|c|c|c|}
\hline Isolates & Source & $\begin{array}{l}\text { Virulence factors } \\
\text { (genes) }\end{array}$ & Antibiotics resisted \\
\hline P. mirabilis 1 & Aspirate & eaeA & CTX, CFM, CIP, CN, SAM, C, CAZ \\
\hline P. mirabilis 2 & Urine & $\begin{array}{l}\text { papC, iutA, fyuA, } \\
\text { traT, bssS }\end{array}$ & CTX, CFM, F, CIP, CN, C, IPM \\
\hline P. mirabilis 3 & Urine & $\begin{array}{l}\text { fim } \mathrm{H}, \text { eaeA, iut } \mathrm{A} \\
\text { fyu } \mathrm{A}, \text { bss }\end{array}$ & CTX. CFM, F, CN, SAM, C \\
\hline P. mirabilis 4 & Stool & fim $\mathrm{H}$, papC, iutA & $\begin{array}{l}\text { MEM, CTX, CFM, F, CIP, CN, SAM, } \\
\text { AK, C, CAZ, IPM }\end{array}$ \\
\hline P. mirabilis 5 & Urine & Iss & $\begin{array}{l}\text { MEM, CTX, CFM, F, CIP, CN, C, } \\
\text { CAZ, IPM }\end{array}$ \\
\hline P. mirabilis 6 & W/swab & iutA & MEM, CTX, CFM, SAM, CAZ, IPM \\
\hline P. mirabilis 7 & Urine & Nil & $\begin{array}{l}\text { MEM, CTX, CFM, F, CIP, CN, SAM, } \\
\text { AK, C, CAZ, IPM }\end{array}$ \\
\hline P. mirabilis 8 & Urine & iutA & $\begin{array}{l}\text { MEM, CTX, CFM, F, CIP, CN, SAM, } \\
\text { CAZ, IPM }\end{array}$ \\
\hline P. mirabilis 9 & Urine & iutA, fyuA, iss, bssS & CTX, CFM, CN, SAM, C, CAZ \\
\hline
\end{tabular}

Table 5. Virulence genes detected with corresponding resistance pattern and their clinical source for K. pneumoniae

\begin{tabular}{llll}
\hline Isolates & Source & \multicolumn{1}{c}{$\begin{array}{c}\text { Virulence factors } \\
\text { (genes) }\end{array}$} & \multicolumn{1}{c}{ Antibiotics resisted } \\
\hline K.pneum 1 & W/swab & Nil & CTX, CFM, F, CIP, CN, SAM, C, CAZ \\
\hline K.pneum 2 & Stool & Nil & CTX, CFM, CIP, CN, SAM, C, CAZ \\
\hline K.pneum 3 & Stool & sfaS, eaeA, fyuA, traT & CTX, CFM, CIP, SAM, AK, C \\
\hline K.pneum 4 & Urine & $\begin{array}{l}\text { papC, sfaS, fyuA, traT, } \\
\text { bssS }\end{array}$ & $\begin{array}{l}\text { MEM, CTX, CFM, CIP, CN, SAM, } \\
\text { C, CAZ }\end{array}$ \\
\hline
\end{tabular}

\section{DISCUSSION}

Over the past few decades, E. coli and K. pneumoniae have emerged as major causes of several infections ranging from community to hospital-acquired infections as a result of being difficult to treat. This study was carried out to determine the AMR and virulence factors in E. coli, K. pneumoniae and P. mirabilis isolated from clinical samples at UDUTH Sokoto, north-west Nigeria.

The preponderance of E. coli, as seen from previous studies, caused their inclusion in this study, and because $E$. coli is the predominant facultative anaerobe and commensal microbiota in the mammalian gastrointestinal tract $[15,16]$ that play a key role in hospital and community acquired infections [17]. Additionally, E. coli strains posses a store of virulence factors that contribute to their ability to overcome different defence mechanisms causing disease [18]. There are few reported studies on virulence factors related to $K$. pneumoniae and $P$. mirabilis. This will therefore serve as a pioneer study in Sokoto, north-western Nigeria.

A biochemical test/identification kit revealed 36 bacterial species (E. coli, K. pneumoniae, and P. mirabilis). There are situations in which the number of species identified by biochemical test may differ with that of an identification kit. The reason for the discrepancy in the number of identified organisms may be attributed to factors such as media specification, specific microorganisms, and cultivation conditions, which are common with biochemical methods frequently characterized by false positive results. This occurs most especially when dealing with a plethora of similar microorganisms. The interpretation of similar organisms might be difficult with the biochemical method, and this may lead to incorrect identification of these organisms. In the clinical settings and public health surveillance, it has been found out that one of the major challenges is the rapid and accurate identification of infectious agents [1]. In the current study, aside from the traditional biochemical method for bacterial identification, a microbial identification kit was used. The rationale for the use of these methods was to ensure that organisms were identified to the species level, although the semi-automatic based method (use of identification kit) is more discriminatory and sensitive, compared to the traditional biochemical method. The use of biochemical tests as a means of identification of microorganisms is routine in resource-limited settings. The setting in which the current study was conducted largely depended on traditional biochemical tests as a means of identification. The major limitations of traditional biochemical tests are its labour intensiveness, as well as material consumption. As pointed out by Srinivasan et al., (2015) following culture, there should be further biochemical and antimicrobial resistance testing [1], which adds to the delayed nature of the whole process. As such, the issue of empirical or inappropriate treatment of infection will be a common practice in such settings. Despite its time consuming and frequent failure in producing accurate results, it also has the disadvantage of allowing the clinician to use inappropriate therapeutic options. Nevertheless, molecular testing as reported [19, 20, 21] usually allows quite a large number of microorganisms from clinical isolates for their identification which are highly specific and sensitive to give a rapid identification, without the need to culture these microorganisms.

Despite the discovery and widespread use of an antimicrobial agent which hindered the spread of pathogens, worse still, there is a global increase in AMR [22]. The threat of AMR is growing at an alarming rate and the situation is perhaps aggravated in developing countries due to the gross abuse of antimicrobials $[23,24]$. A bacterium can present different resistance phenotypes; such as MDR, if the bacterium present is resistant to at least 1 agent in 3 or more antimicrobial categories, while pandrug resistant (PDR) means 'resistant to all antimicrobial agents' [5]. It has been further noted that for a bacterial isolate or species to be characterized as PDR, it must be tested and found to be resistant to all approved and useful agents. In the current study, 3 isolates (E. coli 3, P. mirabilis 4 and P. mirabilis 7) were resistant to all antibiotics tested, although 11 different antibiotics were tested from 5 different classes on these isolates. This may not be sufficient reason to conclude that these isolates are PDR, because definitions of PDR are: 'resistant to almost all commercially available antimicrobials', 'resistant to all antimicrobials routinely tested' and 'resistant to all antibiotic classes available for empirical treatment' makes the definition of PDR subject to inconsistent use, and liable to the potential misinterpretation of data [5]. The ability of the majority of these organisms to resist the effect of antimicrobials, might complicate the treatment of common infections. It is a challenge to treat infections in low- and middle-income countries because there has been an increase in resistance to first-line treatments due to the extended use, misuse, and abuse of antibiotics [25, 26], as the limited availability of antibiotics in stock in these areas has been indicated as a big 
challenge in treating infections. However, in the study area of the authors of this study, there is unrestricted availability of antibiotics, thus likely contributing to the abuse and misuse of antibiotics.

This study revealed a high resistant rate among the isolates for cefixime (100\%), cefotaxime (97.2\%) and ceftazidime $(77.7 \%$, all of which are cephalosporins not routinely or commonly used in the study area. By implication, these isolates are likely extended-spectrum beta-lactamase (ESBL) producers. And when the co-resistance of ceftazidime and cefotaxime in the isolates were compared, $75 \%$ of them isolates were resistant to both antibiotics. This may be connected to the earlier assumption of the authors that the isolates are likely to be producers of ESBL. The carbapenems (meropenem and imipenem) used in this study have shown that some isolates were resistant to their action. This is because $25 \%$ of the isolates were resistant to both imipenem and meropenem, an indication that these isolates are likely carbapenemase producers [27]. The AMR test results showed that none of the isolates were resistant to less than 4 antimicrobials tested so far, although a high sensitivity was recorded to amikacin (80.6\%). Studies by Giwa et al., (2018), and Boroumand et al., (2019) recorded similar results of isolates showing high sensitivity to amikacin [28, 29]. Even among the aminoglycosides currently available for use in humans, the most resistant to the action of aminoglycoside modifying enzymes is amikacin [30].

A study conducted by Beceiro et al. showed that bacteria virulence and antimicrobial resistance develop at different time scales [22], these bacteria mechanisms enable them to overcome the defense systems of the host [22]. This study evaluated some selected genes that encoded these genes (bacteria virulence and antimicrobial resistance) and proffer possible antibiotics that could be used to treat MDR associated with their characteristics in clinical settings. The study also revealed the biofilm encoding gene (bss S) as the most prevalent harboured gene, which was detected among E. coli, K. pneumoniae and P. mirabilis, with the highest prevalence $(47.2 \%)$ in E. coli. This was revealed in similar studies [14, 31].

The ability to colonize and produce biofilm by bacteria is facilitated by adhesive structures which, in addition, was able to restrict antibiotic penetration into the cells [32]. The production of biofilm in bacteria can serve as a means of protection from exposure to antimicrobials, when compared with non-biofilm producing bacteria [33], as well a factor that plays a key role in the development of hospital-acquired infections and urinary tract infections (UTIs) [29].

There was a significant association between surface adhesion genes with resistance to non-beta-lactam antibiotics, as reported by [18], thereby suggesting the inhibitory role of adhesions in the infiltration of drugs in these organisms. The gene for adhesion $(f i m \mathrm{H})$ and iron chelation (iutA) were detected only in E.coli (38.9\% and 27.8\%) and P. mirabilis (5.6\% and $16.7 \%)$, respectively. Adhesion virulence genes confer the organisms the ability to colonize different niches. It has been reported that type 1 and type 3 fimbria play a major role in the attachment of Enterobacteriaceae to the host epithelial and endothelial cells $[32,34]$, as this is important to the organism in colonizing different niches and can also result in the increased pathogenicity of the organism [14]. Although, different bacterial adhesins are adapted to colonize a specific niche [35], a combination of fim $\mathrm{H}$ and traT genes in clinical isolates is said to increase their pathogenicity and capacity to cause illness in their host [32]. This will serve as a means or a strategy for survival in all conditions the organisms may find themselves. Rahdar et al. (2015), and Duzgun et al. (2019), also reported similar results in their studies $[36,37]$. Of the other genes for adhesion, papC was found to be relatively higher than sfaS.

Iron is an essential element in almost all living organisms and is utilized to catalyze a wide variety of vital enzymatic reactions [38]. Of the genes conferring iron chelation ability, iut $\mathrm{A}$ and $f y u \mathrm{~A}$ had a prevalence rate of $44.4 \%$ and $27.8 \%$, respectively. The affinities of bacterial siderophores to iron are generally higher than those of the host molecules, thereby allowing the pathogens to compete with the host in the acquisition of iron [38]. Sáez-López et al. (2016) reported similar results in studies conducted in Rabat, Morocco, and Manhica, southern Mozambique, where iutA and fyuA are the most prevalent virulence genes in vaginal E. coli [25]. A similar result was reported in [39] which reported a high percentage of iutA and fyuA genes in both ESBL and AmpC producing isolates.

Among the genes conferring serum resistance, $\operatorname{traT}(25 \%)$ was the most predominant. The normal serum in mammals has bactericidal activity against a wide range of Gramnegative bacteria [14]. It is also noted that the pathogenicity of bacteria possessing the serum resistance gene is partly a function of their ability to evade the bacterial effect of serum [40].

In the current study, the toxins genes were the least detected, with $s t x 1(13.9 \%)$ more predominant than stx2 (2.8\%), ast $\mathrm{A}$ was completely absent in all isolates, while eaeA (33.3\%) was the most predominant among the toxins genes. However, the study revealed 2 isolates which resisted all the antimicrobials tested, but only presented with 3 of the virulence genes, while 2 of the organisms with the highest number of virulence genes resisted 8 different antibiotics. An interesting finding in the current study was an isolate (P. mirabilis 7) which resisted all antibiotics yet was avirulent (no virulence genes detected by PCR) with other isolates which exhibited a high degree of resistance to 6-9 antimicrobials also found to be avirulent.

Taken together, there appears to be no clear relationship between antibiotic resistance and the virulence gene profiles of the isolates in this study. For example, $P$. mirabilis 7 was resistant to all antibiotics tested against it, but no virulence gene was detected. Also seen in K. pneumoniae 1 and K. pneumoniae 2, no virulence gene was detected, although they are resistant to 8 and 7 antibiotics, respectively. In the case of E. coli 15 and E. coli 13, they were resistant to 9 antibiotics, but onlyl and 2 virulence genes were detected, respectively.

\section{CONCLUSIONS AND RECOMMENDATIONS}

The study showed that all the isolates evaluated were MDR. Some isolates displayed high resistance to antimicrobials yet does not possess any of the virulence genes. Further studies at the molecular level are necessary to investigate the association between virulence factors and antimicrobial resistance, as well as gene expression and the assessment of virulence. 


\section{REFERENCES}

1. Srinivasan R, Karaoz U, Volegova M, Mackichan J, Kato M. Use of 16S rRNA Gene for Identification of a Broad Range of Clinically Relevant Bacterial Pathogens. PLoS One. 2015; 1-22.

2. Iii J, Clarridge E. Impact of $16 \mathrm{~S}$ rRNA Gene Sequence Analysis for Identification of Bacteria on Clinical Microbiology and Infectious Diseases. Clin Microbiol Rev. 2004; 17(4): 840-862.

3.Limmathurotsakul D, Dunachie S, Fukuda K, Feasey NA, Okeke IN, Frcp AHH, et al. Personal View Improving the estimation of the global burden of antimicrobial resistant infections. Lancet Infect Dis. 2019; 3099. http://dx.doi.org/10.1016/S1473-3099(19)30276-2

4. Khalifa HO, Soliman AM, Ahmed AM, Shimamoto T, Nariya H, Matsumoto T, et al. High Prevalence of Antimicrobial Resistance in Gram-negative Bacteria Isolated from Clinical Settings in Egypt: Recalling for Judicious Use of Conventional. Microbiol Drug Resist. 2019; 00(00): 1-15.

5. Magiorakos AP, Srinivasan A, Carey RB, Carmeli Y, Falagas ME, Giske CG, et al. Multidrug-resistant, extensively drug-resistant and pandrugresistant bacteria: An international expert proposal for interim standard definitions for acquired resistance. Clin Microbiol Infect. 2012; 18(3): 268-281. http://dx.doi.org/10.1111/j.1469-0691.2011.03570.x

6. Chong Y, Shimoda S, Shimono N. Current epidemiology, genetic evolution and clinical impact of extended-spectrum beta-lactamaseproducing Escherichia coli and Klebsiella pneumoniae. Infection, Genetics and Evolution. 2018; 61.

7.Munoz-Price SL, Laurent P, Bonomo RA, Schwaber MJ, Daikos GL Cormican M, et al. Lancet Infect Dis. 2013; 13(9): 785-796.

8. Jasovsky D, Littmann J, Zorzet A, Cars O. Antimicrobial ResistanceA Threat to the World's Sustainable Development. Dev Dialogue Pap. 2016; 16: 1-8.

9. Jim O. Antimicrobial Resistance: Tackling a crisis for the health and wealth of nations. Rev Antimicrob Resist. 2014; 1-20.

10. Giraud E, Rychlik I, Cloeckaert A. Antimicrobial Resistance and Virulence Common Mechanisms. Front Cell Infect Microbiol. 2017; 8: $1-3$.

11. Schmidt H, Hensel M. Pathogenicity Islands in Bacterial Pathogenesis Clin Microbiol Rev. 2004; 17(1): 14-56. http://dx.doi.org/10.1016/j. ejbt.2015.09.003

12. Chapman TA, Wu XY, Barchia I, Bettelheim KA, Driesen S, Trott D, et al. Comparison of virulence gene profiles of Escherichia coli strains isolated from healthy and diarrheic swine. Appl Environ Microbiol 2006; 72(7): 4782-4795.

13. Barbosa C, Nogueira S, Gadanho M, Chaves S. DNA extraction: Finding the most suitable method. Molecular Microbial Diagnostic Methods: Pathways to Implementation for the Food and Water Industries. Elsevier Inc. 2015: 135-154. http://dx.doi.org/10.1016/B978-0-12-4169999/00007-1

14.El-shaer S, Abdel-rhman SH, Barwa R, Hassan R. Virulence Characteristics, Serotyping and Phylogenetic Typing of Clinical and Environmental Escherichia coli Isolates. Jundishapur J Microbiol. 2018 11(12): 1-12.

15. Abimiku RH, Ngwai YB, Nkene IH, Bassey BE, Tsaku PA, Ibrahim T, et al. Phenotypic Detection of Extended Spectrum Beta-lactamase Resistance of Escherichia coli from Patients Attending Selected Healthcare Facilities in Nasarawa State, Nigeria. South Asian J Res Microbiol. 2019; 4(3): 1-10.

16. Adenipekun EO, Jackson CR, Ramadan H, Iwalokun BA, Oyedeji KS Frye JG, et al. Prevalence and multidrug resistance of Escherichia coli from community-acquired infections in Lagos, Nigeria. J Infect Dev Ctries. 2016; 10(9): 920-931.

17. Kpoda DS, Guessennd N, Bonkoungou JI, Ouattara MB, Konan F, Ajayi A, et al. Prevalence and resistance profile of extended-spectrum betalactamases-producing Enterobacteriaceae in Ouagadougou, Burkina Faso. African J Microbiol Res. 2017; 11(27): 1120-1126.

18. Dadi BR, Abebe T, Zhang L, Mihret A, Abebe W, Amogne W. Distribution of virulence genes and phylogenetics of uropathogenic Escherichia coli among urinary tract infection patients in Addis Ababa, Ethiopia. BMC Infect Dis. 2020; 20: 1-12.

19. Eric L, Hunfeld LK, Emrich T, Haberhausen G, Wissing H, Hoeft A, et al. A multiplex real-time PCR assay for rapid detection and differentiation of 25 bacterial and fungal pathogens from whole blood samples. Med Microbiol Immunol. 2008; 197: 313-324.

20. Hallin M, Maes N, Byl B, Jacobs F, Gheldre Y De, Struelens MJ. Clinical Impact of a PCR Assay for Identification of Staphylococcus aureus and
Determination of Methicillin Resistance Directly from Blood Cultures. J Clin Microbiol. 2003; 41(8): 3942-3944.

21. Barbut F, Monot M, Rousseau A, Cavelot S, Simon T, Burghoffer B, et al. Rapid diagnosis of Clostridium difficile infection by multiplex real-time PCR. Eur J Clin Microbiol Infect Dis. 2011; 30: 1279-1285.

22. Beceiro A, Tomás M, Bou G. Antimicrobial resistance and virulence: A successful or deleterious association in the bacterial world? Clin Microbiol Rev. 2013; 26(2): 185-230.

23. Ayukekbong JA, Ntemgwa M, Atabe AN. The threat of antimicrobial resistance in developing countries: causes and control strategies. Antimicrob Resist Infect Control. 2017; 6(47): 1-8.

24. Ouedraogo AS, Sanou M, Kissou A, Sanou S, Solaré H, Kaboré F, et al. High prevalence of extended-spectrum beta-lactamase producing Enterobacteriaceae among clinical isolates in Burkina Faso. BMC Infect Dis. 2016; 16(1): 1-9. http://dx.doi.org/10.1186/s12879-016-1655-3

25. Sáez-lópez E, Cossa A, Benmessaoud R, Madrid L. Characterization of Vaginal Escherichia coli Isolated from Pregnant Women in Two Different African Sites. PLoS One. 2016; 1-10.

26. Mshana SE, Matee M, Rweyemamu M. Antimicrobial resistance in human and animal pathogens in Zambia, Democratic Republic of Congo, Mozambique and Tanzania: an urgent need of a sustainable surveillance system. Ann Clin Microbiol Antimicrob. 2013; 12(1): 1.

27. Ugwu MC, Igbokwe JO, Okezie U, Eze PM, Ejikeugwu CP, Esimone CO. Prevalence of ESBLs and MBLs among Escherichia coli and Klebsiella pneumoniae isolates from a Nigerian Abattoir. J Trop Dis. 2018; 6(2): 2-6.

28. Giwa FJ, Ige OT, Haruna DM, Yaqub Y, Lamido TZ US. Extended-Spectrum Beta-lactamase Production and Antimicrobial Susceptibility Pattern of Uropathogens in a Tertiary Hospital in Northwestern Nigeria. Ann Trop Pathol. 2018; 9: 11-16.

29. Boroumand M, Sharifi A, Manzouri L, Khoramrooz SS, Khosravani A. Evaluation of pap and sfa Genes Relative Frequency P and S Fimbriae Encoding of Uropathogenic Escherichia coli Isolated from Hospitals and Medical Laboratories; Yasuj City, Southwest Iran. Iran Red Crescent Med J. 2019; 21(8): 1-8.

30. Ramirez MS, Tolmasky ME. Amikacin: Uses, Resistance, and Prospects for Inhibition. Molecules. 2017; 22(1957).

31. Gharrah MM, Mostafa El-Mahdy A, Barwa RF. Association between Virulence Factors and Extended Spectrum Beta-Lactamase Producing Klebsiella pneumoniae Compared to Non-producing Isolates. Interdiscip Perspect Infect Dis. 2017; 2017(27): 251-264.

32. Ghasemian A, Mobarez AM, Peerayeh SN, Abadi ATB. The association of surface adhesin genes and the biofilm formation among Klebsiella oxytoca clinical isolates. New Microbes New Infect. 2019; 27: 36-39. https://doi.org/10.1016/j.nmni.2018.07.001

33. Bellifa S, Hassaine H, Balestrino D, Charbonnel N, Imane M, Terki IK, et al. Evaluation of biofilm formation of Klebsiella pneumoniae isolated from medical devices at the University Hospital of Tlemcen, Algeria. African J Microbiol Res. 2013; 7(49): 5558-5564.

34. Sarkar S, Vagenas D, Schembri MA, Totsika M. Biofilm formation by multidrug resistant Escherichia coli ST131 is dependent on type 1 fimbriae and assay conditions. Pathog Dis. 2016; 74: 1-5.

35. Sarowska J, Koloch BF, Kmiecik AJ, Madrzak MF, Ksiazczyk M, Ploskonska GB, et al. Virulence factors, prevalence and potential transmission of extraintestinal pathogenic Escherichia coli isolated from different sources: recent reports. Gut Pathog. 2019; 11(10): 1-16. https://doi.org/10.1186/s13099-019-0290-0

36. Rahdar M, Rashki A, Miri HR, Ghalehnoo MR. Uropathogenic Escherichia coli Isolates Collected From Patients With Urinary Tract Infection. Jundishapur J Microbiol. 2015; 8(8): 1-6.

37. Düzgün AÖ, Okumuş F, Saral A. Determination of antibiotic resistance genes and virulence factors in Escherichia coli isolated from Turkish patients with urinary tract infection. J Brazilian Soc Trop Med. 2019, 52: $1-5$.

38. Wilson BR, Bogdan AR, Miyazawa M, Hashimoto K. Siderophores in Iron Metabolism: From Mechanism to Therapy Potential. Trends Mol Med. 2017; 22(12): 1077-1090.

39. Abdelmegeed ES, Barwa R, Abd KH, Galil E. Comparative study on prevalence and association of some virulence factors with extended spectrum beta-lactamases and AmpC producing Escherichia coli. African J Microbiol Res. 2015; 9(17): 1165-74.

40. Hassan R, El-Naggar W, El-Sawy E, E-MA. Characterization of Some Virulence Factors Associated with Enterbacteriaceae Isolated From Urinary Tract Infections in Mansoura Hospitals. Egypt J Med Microbiol. 2011; 20(2): 9-17. 